NATIONAL LABORATORY

\title{
Fuel Economy and Emissions of a Vehicle Equipped with an Aftermarket Flexible-Fuel Conversion Kit
}

\section{April 2012}

Prepared by John F. Thomas Shean P. Huff Brian H. West

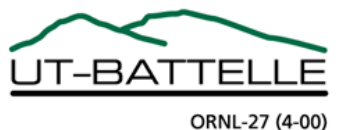




\section{DOCUMENT AVAILABILITY}

Reports produced after January 1, 1996, are generally available free via the U.S. Department of Energy (DOE) Information Bridge.

\section{Web site http://www.osti.gov/bridge}

Reports produced before January 1, 1996, may be purchased by members of the public from the following source.

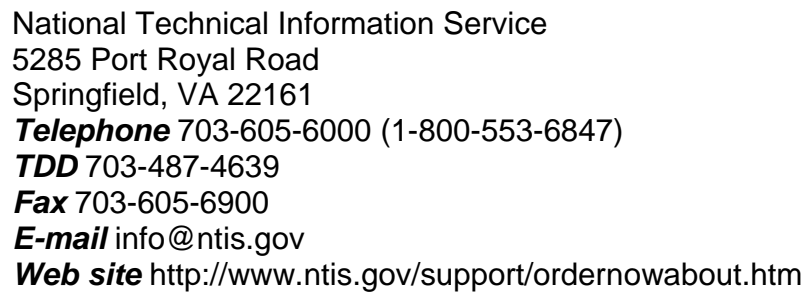

Reports are available to DOE employees, DOE contractors, Energy Technology Data Exchange (ETDE) representatives, and International Nuclear Information System (INIS) representatives from the following source.

Office of Scientific and Technical Information

P.O. Box 62

Oak Ridge, TN 37831

Telephone 865-576-8401

Fax 865-576-5728

E-mail reports@osti.gov

Web site http://www.osti.gov/contact.html

This report was prepared as an account of work sponsored by an agency of the United States Government. Neither the United States Government nor any agency thereof, nor any of their employees, makes any warranty, express or implied, or assumes any legal liability or responsibility for the accuracy, completeness, or usefulness of any information, apparatus, product, or process disclosed, or represents that its use would not infringe privately owned rights. Reference herein to any specific commercial product, process, or service by trade name, trademark, manufacturer, or otherwise, does not necessarily constitute or imply its endorsement, recommendation, or favoring by the United States Government or any agency thereof. The views and opinions of authors expressed herein do not necessarily state or reflect those of the United States Government or any agency thereof. 
ORNL/TM-2011/483

Vehicle Technologies Program

\title{
FUEL ECONOMY AND EMISSIONS OF A VEHICLE EQUIPPED WITH AN AFTERMARKET FLEXIBLE-FUEL CONVERSION KIT
}

\author{
John F. Thomas \\ Shean P. Huff \\ Brian H. West \\ Oak Ridge National Laboratory
}

Date Published: April 2012

Prepared by

OAK RIDGE NATIONAL LABORATORY

Oak Ridge, Tennessee 37831-6283

managed by

UT-BATTELLE, LLC

for the

U.S. DEPARTMENT OF ENERGY

under contract DE-AC05-00OR22725 



\section{CONTENTS}

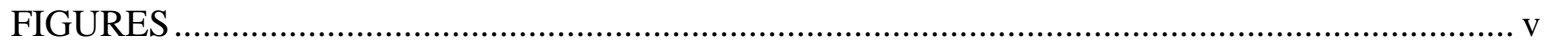

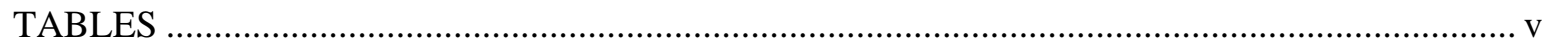

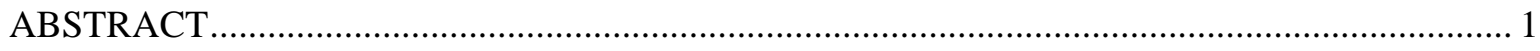

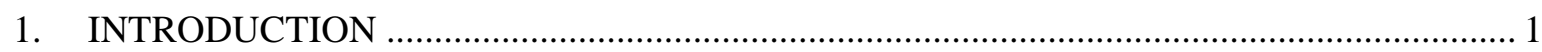

2. EXPERIMENTAL SETUP AND PROCEDURES ….............................................................. 2

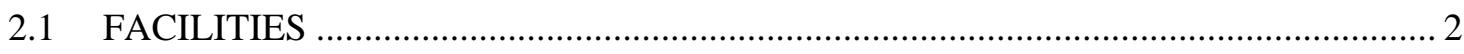

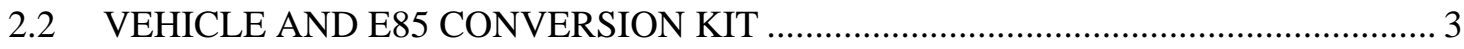

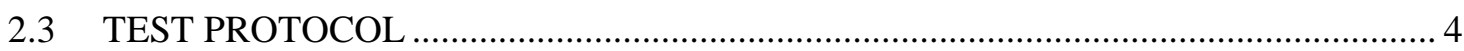

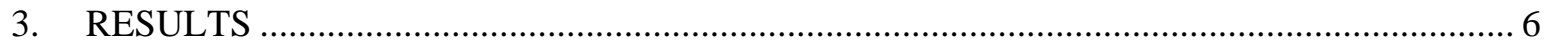

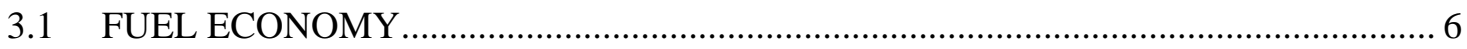

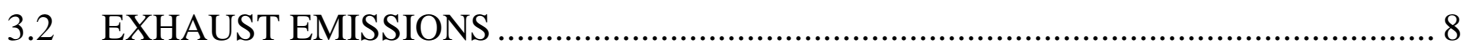

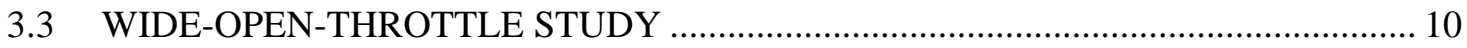

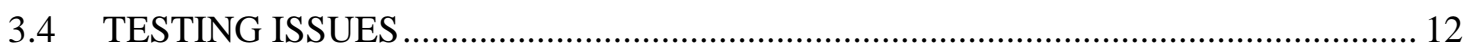

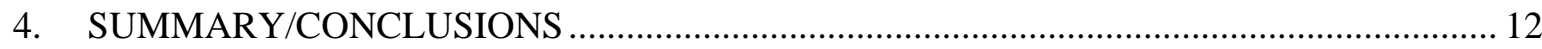

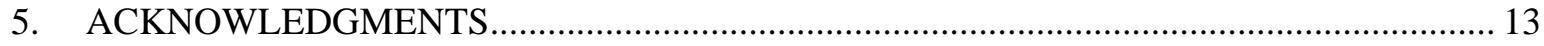





\section{FIGURES}

1. Flex Box Smart Kit controller installed (left); ninth fuel injector and injector

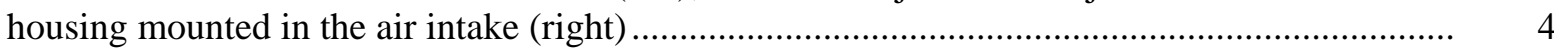

2. Dodge Charger under test in the FEERC vehicle laboratory ….............................................. 5

3. Average fuel economy for test fuels over the FTP, HFET, and US06 drive

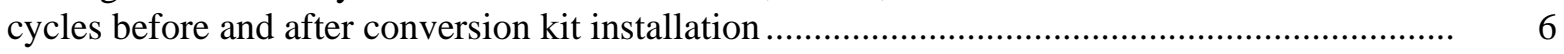

4. $\quad$ E85 fuel economy versus gasoline fuel economy for U.S.-Legal FFVs .................................... 7

5. Average $\mathrm{NO}_{\mathrm{X}}$ emissions for test fuels over the FTP, HFET, and US06 drive cycles before and after conversion kit installation .................................................................... 8

6. Average CO emissions for test fuels over the FTP, HFET, and US06 drive cycles before and after conversion kit installation ...................................................................

7. Average FTP NMOG emissions with breakdown for nonoxygenated nonmethane hydrocarbons (NONMHC), ethanol (EtOH), formaldehyde (Form.) and

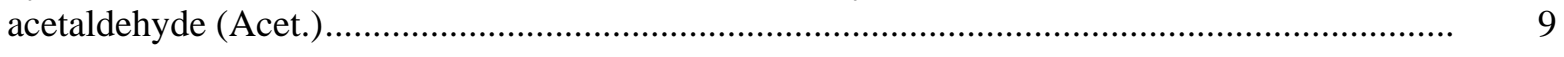

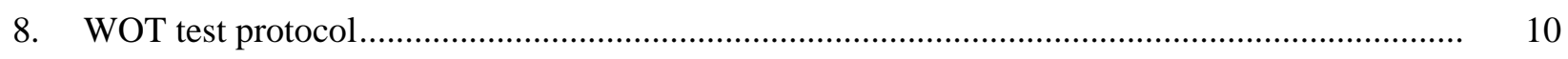

9. Catalyst temperature for E0 and E20 fuels during WOT testing in the OEM condition.............. 11

10. Catalyst temperature for each fuel during WOT testing after installation of FFV kit ................. 11

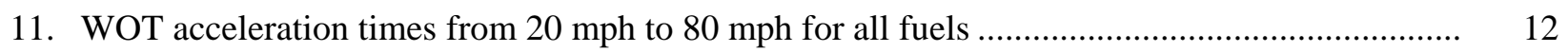

\section{TABLES}

1. Selected properties of gasoline and gasoline-ethanol test fuels ............................................... 4

2. Experimental test matrix used for the Dodge Charger before and after conversion kit installation 



\begin{abstract}
The U.S. Environmental Protection Agency (EPA) grants Certificates of Conformity for alternative fuel conversion systems and also offers other forms of premarket registration of conversion kits for use in vehicles more than two model years old. ${ }^{*}$ Use of alternative fuels such as ethanol, natural gas, and propane are encouraged by the Energy Policy Act of 1992. Several original equipment manufacturers (OEMs) produce emissions-certified vehicles capable of using alternative fuels, and several alternative fuel conversion system manufacturers produce EPA-approved conversion systems for a variety of alternative fuels and vehicle types. To date, only one manufacturer (Flex Fuel U.S.) has received EPA certifications for ethanol fuel (E85) conversion kits.

This report details an independent evaluation of a vehicle with a legal installation of a Flex Fuel U.S. conversion kit. A 2006 Dodge Charger was baseline tested with ethanol-free certification gasoline (E0) and E20 (gasoline with $20 \mathrm{vol} \%$ ethanol), converted to flex-fuel operation via installation of a Flex Box Smart Kit from Flex Fuel U.S., and retested with E0, E20, E50, and E81. Test cycles included the Federal Test Procedure (FTP or city cycle), the highway fuel economy test (HFET), and the US06 test (aggressive driving test).

Averaged test results show that the vehicle was emissions compliant on E0 in the OEM condition (before conversion) and compliant on all test fuels after conversion. Average nitrogen oxide (NOx) emissions exceeded the Tier 2/Bin 5 intermediate life $\mathrm{NO}_{\mathrm{X}}$ standard with E20 fuel in the OEM condition due to two of three test results exceeding this standard [note that E20 is not a legal fuel for non-flexible-fuel vehicles (non-FFVs)]. In addition, one E0 test result before conversion and one E20 test result after conversion exceeded the $\mathrm{NO}_{\mathrm{X}}$ standard, although the average result in these two cases was below the standard. Emissions of ethanol and acetaldehyde increased with increasing ethanol, while nonmethane organic gas and $\mathrm{CO}$ emissions remained relatively unchanged for all fuels and cycles. Higher fraction ethanol blends appeared to decrease $\mathrm{NO}_{\mathrm{X}}$ emissions on the FTP and HFET (after conversion). As expected, fuel economy (miles per gallon) decreased with increasing ethanol content in all cases.
\end{abstract}

\title{
1. INTRODUCTION
}

The Energy Independence and Security Act of 2007 (EISA) expands the renewable fuel standard to require the use of 36 billion gallons of renewable fuel per year by 2022. Given that ethanol is the most widely used renewable fuel in the U.S. market, ethanol will likely make up a significant portion of the 36-billion-gallon requirement.

The vast majority of the ethanol used for transportation in the United States is blended with gasoline to create E10-gasoline with up to 10\% ethanol. The remaining ethanol is sold in higher level blends for use in FFVs, vehicles that can operate on any blend of gasoline and ethanol between ethanol-free gasoline (E0) and E85. ASTM International's standard ASTM D 5798-11 defines "ethanol fuel blends for flexiblefuel automotive spark-ignition engines” (known commercially as "E85”) as gasoline blends with 51 to $83 \mathrm{vol} \%$ ethanol. Consumption of E85 in the U.S. is currently limited by the size of the FFV fleet, the number of E85 fueling stations, and sometimes unfavorable pricing of E85 compared to E0 or E10 (on a cost per unit energy basis).

\footnotetext{
${ }^{*}$ U.S. Environmental Protection Agency, On-Road Vehicles and Engines: Alternative Fuel Conversion, available at http://www.epa.gov/otaq/consumer/fuels/altfuels/altfuels.htm\#3.

${ }^{\dagger}$ ASTM International, Standard Specification for Ethanol Fuel Blends for Flexible-Fuel Automotive Spark-Ignition Engines, ASTM D5798-11, ASTM International, West Conshohocken, Pennsylvania, 2011.
} 
The E10 market in the United States reached virtual saturation in 2010 with 13.2 billion gallons of ethanol produced and more than $90 \%$ of gasoline sold as E10. The E85 market has accounted for less than $1 \%$ of the ethanol consumed each year for the past several years ${ }^{*}$ while the remainder is exported or blended in U.S. gasoline at up to 10\% ethanol. Currently there are some 8 million FFVs in the U.S. fleet, accounting for less than $4 \%$ of the light duty fleet. These vehicles consumed only 27 million gallons of E85 in 2010. Clearly, expansion of E85 use has the potential to increase ethanol consumption by several billion gallons per year, which would have a significant positive impact on EISA compliance. Original equipment manufacturers (OEMs) continue to produce a growing number of FFVs, reducing the FFV fleet size limitation. Conceptually, the size of the FFV fleet could be further increased through legal conversion of existing non-FFVs to flex-fuel operation.

This report details an independent evaluation of a 2006 Dodge Charger with a 5.7 liter V8 engine before and after installation of a Flex Fuel U.S. conversion kit. The test vehicle was baseline tested with ethanolfree certification gasoline (E0) and E20 (gasoline with $20 \mathrm{vol} \%$ ethanol), converted to flex-fuel operation via installation of a Flex Box Smart Kit from Flex Fuel U.S., and retested with E0, E20, E50, and E81. [E81 is a common "E85" blend that results from blending 15\% gasoline with 85\% denatured ethanol (the denaturant being $\sim 5 \%$ gasoline or gasoline-range hydrocarbons).]

The tailpipe emission certification testing requirements from the U.S. Environmental Protection Agency (EPA) for aftermarket conversion kits are less comprehensive than those for OEM FFV certification. For aftermarket conversion kits EPA only requires emissions testing on the conversion kit's target fuel (e.g., E85) on the Federal Test Procedure (FTP, or city cycle) and the highway fuel economy test (HFET). Test cycles in this study included the FTP, the HFET, and the US06 aggressive driving test (part of the supplemental FTP). Fuels tested included E0 and E81, as well as ethanol blends E20 and E50 to evaluate the system performance on these mid-level ethanol blends. In addition to the emissions and fuel economy cycles, the modified CRC E-60 wide-open-throttle (WOT) protocol ${ }^{\dagger}$ was conducted to assess open-loop air : fuel ratio control.

\section{EXPERIMENTAL SETUP AND PROCEDURES}

\subsection{FACILITIES}

Vehicle testing was performed at the Oak Ridge National Laboratory's (ORNL's) Fuels, Engines, and Emissions Research Center (FEERC), located at the National Transportation Research Center in Knoxville, Tennessee. The FEERC vehicle research laboratory is equipped with a Burke E. Porter 300 hp motor-in-the-middle, two-wheel drive, 48-inch, single roll AC motoring chassis dynamometer. The dynamometer meets the EPA specifications for large roll chassis dynamometers.

The laboratory is further equipped with three dedicated emissions benches, each with conventional California Analytical Instruments exhaust gas analyzers. Two benches routinely measure raw undiluted emissions (e.g., engine-out and tailpipe emissions), and the third bench samples dilute exhaust from a constant volume sampling system (CVS, or dilution tunnel). The CVS is equipped with three critical flow venturis, allowing several discrete flow rates ranging from 200 to 1,050 CFM. The CVS bag sampler is equipped with conventional analyzers for $\mathrm{CO}, \mathrm{CO}_{2}, \mathrm{NO}_{\mathrm{X}}$ (nitrogen oxide), and total hydrocarbons (THC)

\footnotetext{
*U.S. Energy Information Administration, Monthly Energy Review, DOE/EIA-0035(2011/07), July 27, 2011, available at http://www.eia.gov/FTPROOT/monthlyhistory.htm (last accessed December 2011).

${ }^{\dagger}$ Keith Knoll et al., Effects of Intermediate Ethanol Blends on Legacy Vehicles and Small Non-Road Engines, Report 1Updated, NREL/TP-540-43543/ORNL/TM-2008/117, February 2009, available at http://www.nrel.gov/docs/fy09osti/43543.pdf.
} 
and can also accommodate more advanced emissions instrumentation for particulate matter, ethanol, aldehydes, and other measurements.

The Innova photoacoustic multigas analyzer was used to measure dilute ethanol emissions in all tests, and silica-gel cartridges treated with di-nitrophenylhydrazine were used to trap formaldehyde and acetaldehyde. The cartridges were eluted with acetonitrile and the derivative analyzed with highperformance liquid chromatography. Ethanol, formaldehyde, acetaldehyde, THC, and methane were used to estimate nonmethane organic gas (NMOG) emissions (described in Sect. 3.2).

The laboratory temperature and humidity are regulated and measured. All continuous modal emissions data as well as additional sensors and vehicle controller network information can be acquired by an integrated data acquisition system. The laboratory has been cross-checked against independent certification laboratories, and results are in excellent agreement for fuel economy and vehicle emissions. All tests were conducted at a nominal $77^{\circ} \mathrm{F}$ ambient laboratory temperature.

\subsection{VEHICLE AND E85 CONVERSION KIT}

Flex Fuel U.S. obtained an EPA Certificate of Conformity for several Chrysler engine families, including the 5.7 liter V8 engine in the 2006 Dodge Charger, ${ }^{*}$ which was the vehicle obtained for this study. The 2006 Dodge Charger is equipped from the factory with a port fuel injected 5.7 liter V8 featuring the Multi-Displacement System (cylinder deactivation at some moderate to low loads) and a five speed automatic transmission. The vehicle had less than 30,000 odometer miles at the start of testing.

Because E85 has about 29\% less energy per unit volume than conventional gasoline, the flex-fuel conversion requires increased volumetric fuel delivery rates at increased ethanol levels to produce the same power. To deliver additional fuel, the Flex Box Smart Kit adds a ninth fuel injector in an adaptor mounted between the throttle body and the intake manifold. The conversion kit also includes a fuel composition sensor and an electronic control unit. The system's control unit and the ninth injector are shown installed in the vehicle in Fig. 1. Kit installation also requires splicing wires at the OEM cam sensor and crank sensor to supply those signals to the Flex Box Smart Kit control unit. The OEM fuel line must also be modified to insert the fuel composition sensor and fuel feed for the auxiliary fuel injector. The system was installed in a few hours by an experienced automotive technician following the instructions provided by the conversion kit manufacturer.

It is important to note that installation of aftermarket kits can result in transfer of warranty liability for certain components from the OEM to the converter manufacturer. ${ }^{\dagger}$

\footnotetext{
*EPA Certificates of Conformity issued to Flex Fuel U.S., number: BFLXT05.4R17-002 and 5AFLXV04.6VG8 (certain 2005 and 2006 model year Ford vehicles with 5.4 and 4.6 liter engines, BFLXV03.5MEO-001 and 2009-232T2-02 (certain 2006 and 2007 model year Chrysler 3.5 and 5.7 liter engine vehicles), http://flexfuelus.com/, http://www.epa.gov/otaq/consumer/fuels/altfuels/altfuels.htm\#3, http://iaspub.epa.gov/otaqpub/.

${ }^{\dagger}$ Federal Register, Vol. 76(68), Friday, April 8, 2011, “Clean Alternative Fuel Vehicle and Engine Conversions; Final Rule.”
} 


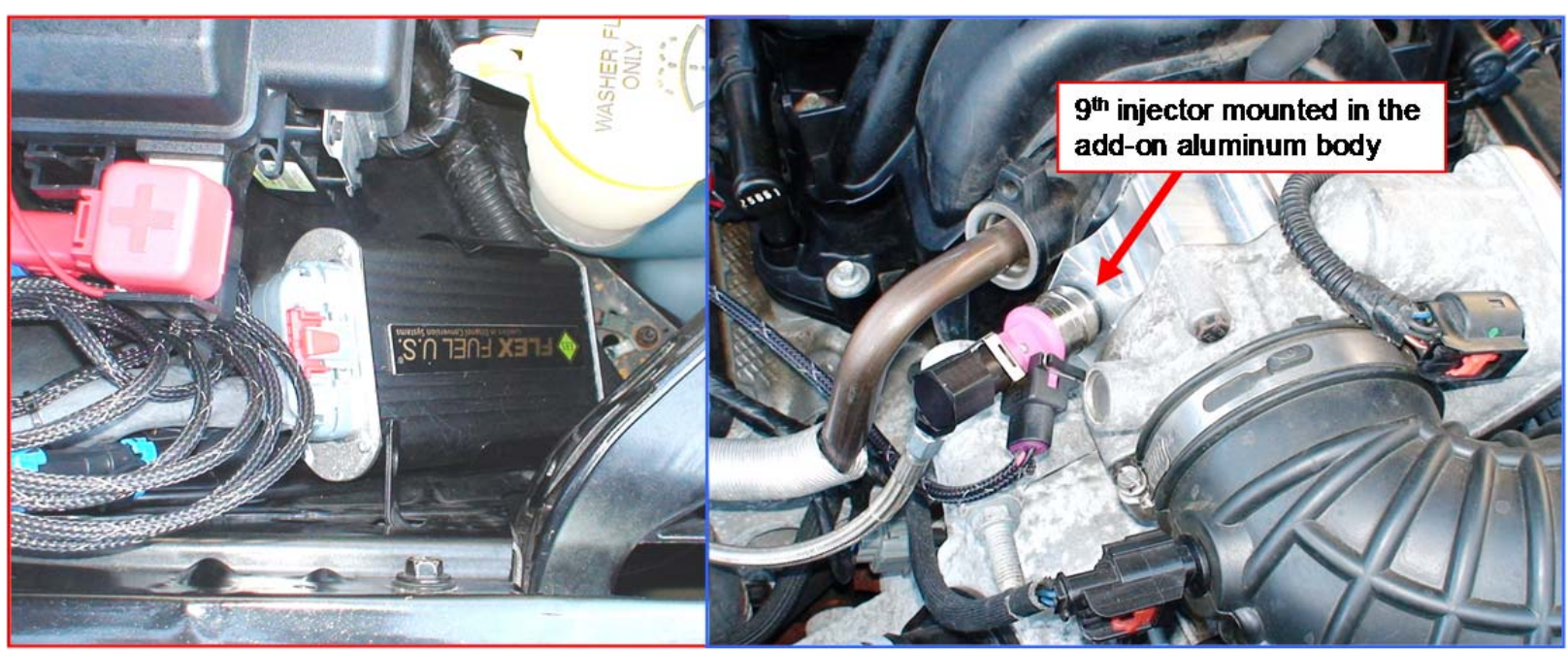

Fig. 1. Flex Box Smart Kit controller installed (left); ninth fuel injector and injector housing mounted in the air intake (right).

\subsection{TEST PROTOCOL}

The Dodge Charger was emissions tested with several fuels over the FTP, HFET, and US06 driving cycles. In addition, the modified CRC E-60 WOT protocol was conducted to assess open-loop air : fuel ratio control. Emissions tests were generally run in triplicate, although in a few cases additional tests were performed. Before the conversion kit was installed, testing was performed in the OEM condition on E0 and E20. After installing the E85 conversion system, the vehicle was tested again using the same E0 and E20, as well as E50 and E81. The same E0 blendstock (Haltermann EEE Federal Certification gasoline) was splash-blended with ethanol meeting ASTM D4806 specifications ${ }^{\dagger}$ to create all test fuels. Southwest Research Institute analyzed all fuels for relevant properties, shown in Table 1. The test matrix is shown chronologically in Table 2.

Table 1. Selected properties of gasoline and gasoline-ethanol test fuels

\begin{tabular}{lccccc}
\hline \multirow{2}{*}{\multicolumn{1}{c}{ Property (units) }} & \multirow{2}{*}{ Test method } & \multicolumn{4}{c}{ Nominal fuel composition } \\
\cline { 3 - 6 } & & E0 Gasoline & E20 & E50 & E81 \\
\hline Carbon mass fraction (\%) & ASTM D5291 & 86.69 & 79.26 & 68.48 & 58.13 \\
Hydrogen mass fraction (\%) & ASTM D5291 & 13.31 & 13.39 & 13.43 & 13.37 \\
Oxygen mass fraction (\%) & ASTM D5599 & $<0.1$ & 7.35 & 18.09 & 28.50 \\
Fuel density (g/ml) & ASTM D4052 & 0.7451 & 0.7528 & 0.7688 & 0.7844 \\
Ethanol (vol \%) & ASTM D5599 & $<0.1$ & 20.08 & 50.49 & 81.17 \\
Lower heating value (Btu/lb) & ASTM D240 & 18,592 & 17,010 & 14,793 & 12,625 \\
Lower heating value calculated & & 115,500 & 106,900 & 94,900 & 82,600 \\
(Btu/gallon) & & & & & \\
\hline
\end{tabular}

*Keith Knoll et al., Effects of Intermediate Ethanol Blends on Legacy Vehicles and Small Non-Road Engines, Report 1Updated, NREL/TP-540-43543/ORNL/TM-2008/117, February 2009, available at http://www.nrel.gov/docs/fy09osti/43543.pdf.

${ }^{\dagger}$ ASTM International, Standard Specification for Denatured Fuel Ethanol for Blending with Gasolines for Use as Automotive Spark-Ignition Engine Fuel, ASTM D4806-11a, ASTM International, West Conshohocken, Pennsylvania, 2011. 
Table 2. Experimental test matrix used for the Dodge Charger before and after conversion kit installation

\begin{tabular}{ll}
\hline \multicolumn{1}{c}{ Vehicle condition, fuel } & Driving cycles (number of tests) \\
\hline OEM condition, E0 & FTP(5), HFET(3), US06(5), WOT \\
OEM condition, E20 & FTP(3), HFET(3), US06(3), WOT
\end{tabular}

\section{Flex-fuel kit installation}

Kit installed, E0

FTP(3), HFET(3), US06(3), WOT

Kit installed, E20

FTP(3), HFET(3), US06(3), WOT

Kit installed, E50

FTP(3), HFET(3), US06(3), WOT

Kit installed, E81

FTP(4), HFET(3), US06(3), WOT $^{a}$

Abbreviations: OEM = original equipment manufacturer, FTP $=$ Federal Test Procedure, HFET = highway fuel economy test, US06 = aggressive driving test, and WOT $=$ wide open throttle.

${ }^{a}$ E81 WOT tests repeated after maintenance (see Sect. 3.4).

After each change in fuel type, the vehicle was driven in a manner that was modeled after the procedure used in the DOE V1 study* (a double US06, an LA4 ${ }^{\dagger}$, and an LA92 ${ }^{\ddagger}$ ) to ensure the vehicle’s fuel control system had ample time to properly adapt to the new fuel (i.e., update the long-term fuel trim). For subsequent tests on the same fuel the "test as prep" protocol was used where the last test of the day was the prep for the next day's cold start test. If more than 36 hours would pass before the next cold start, a single LA 4 test was run as a preparatory cycle at least 12 hours before the cold start test. Figure 2 shows the vehicle under test in the FEERC laboratory.

To facilitate fuel changes, the vehicle’s OEM fuel tank was bypassed and the test fuel was supplied from an external tank.

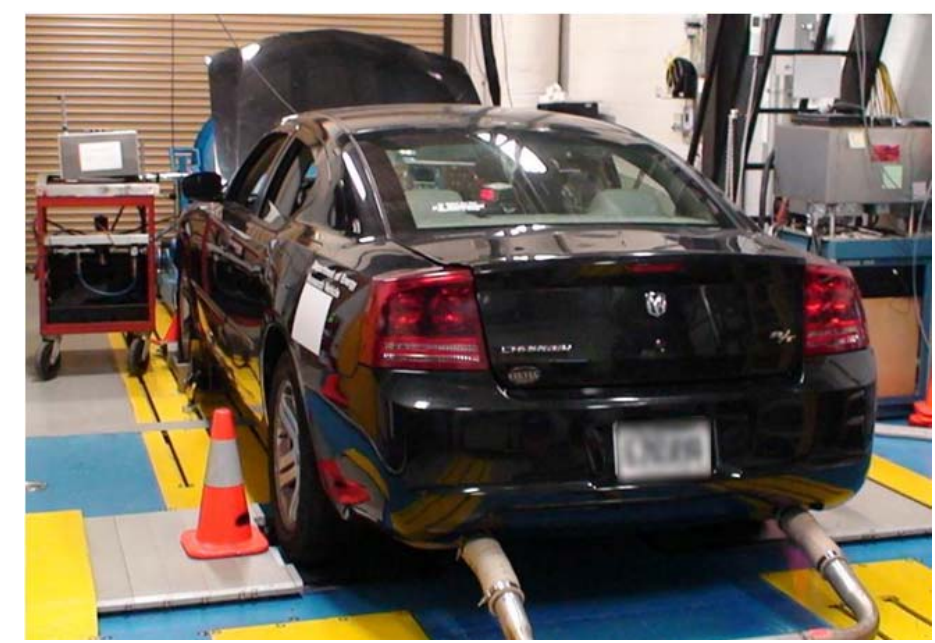

Fig. 2. Dodge Charger under test in the FEERC vehicle laboratory.

${ }^{*}$ Keith Knoll et al., Effects of Intermediate Ethanol Blends on Legacy Vehicles and Small Non-Road Engines, Report 1Updated, NREL/TP-540-43543/ORNL/TM-2008/117, February 2009, available at http://www.nrel.gov/docs/fy09osti/43543.pdf.

${ }^{\dagger}$ The LA4, also known as the Urban Dynamometer Driving Schedule (UDDS) is a 1,372 second cycle that consists of the first two phases of the Federal Test Procedure.

${ }^{\ddagger}$ LA92 is also known as the unified cycle and involves higher speeds and accelerations than the Federal Test Procedure (http://www.arb.ca.gov/msei/onroad/briefs/Publication3.pdf). 


\section{RESULTS}

\subsection{FUEL ECONOMY}

The fuel economy results for the FTP, HFET, and US06 tests are shown in Fig. 3. Columns show the average result, and the range bars show the maximum and minimum of multiple tests. Striped columns indicate baseline data (before conversion), and solid columns indicate data after conversion systems were installed.
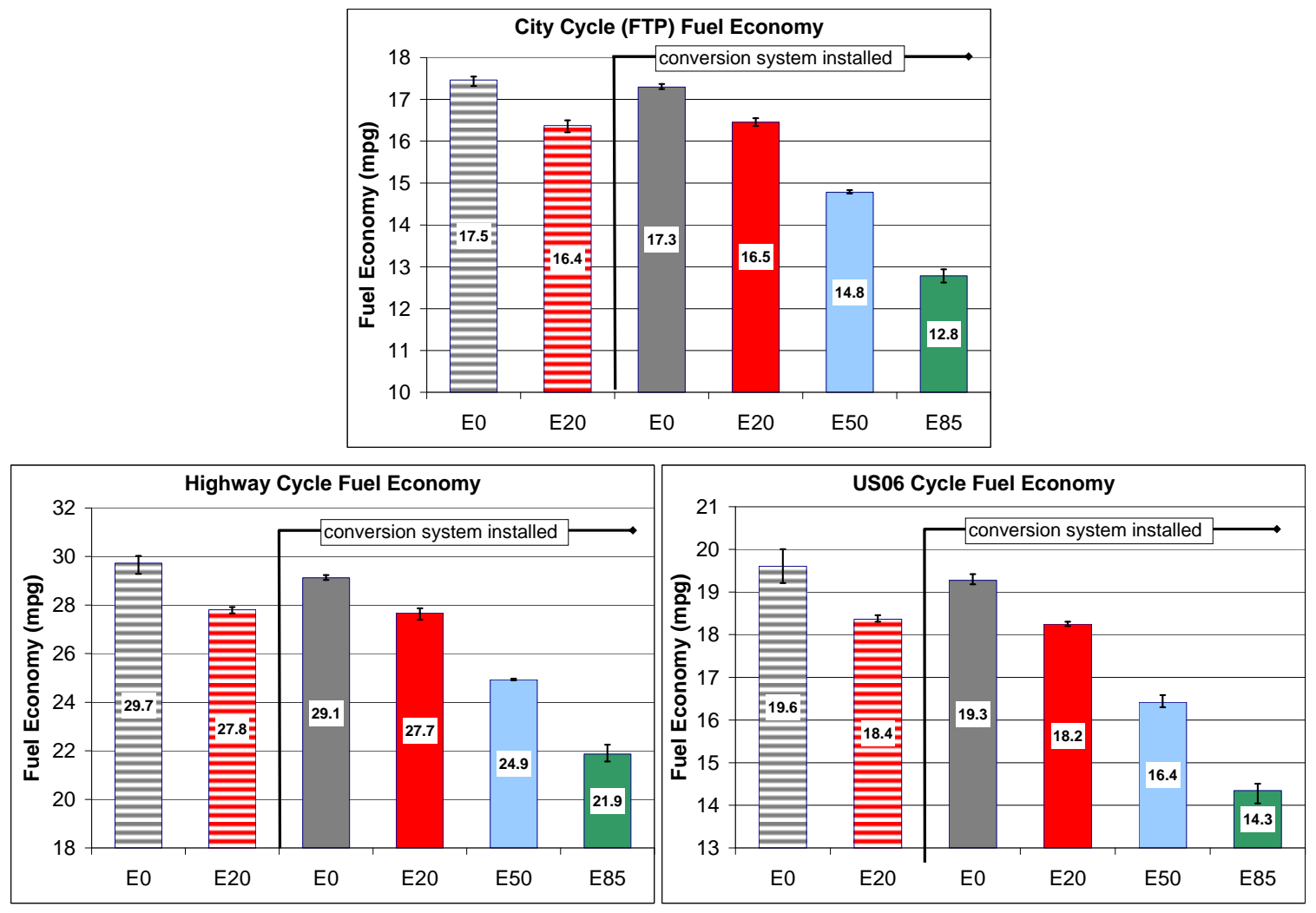

Fig. 3. Average fuel economy for test fuels over the FTP, HFET, and US06 drive cycles before and after conversion kit installation. Range bars show maximum and minimum test results.

Fuel economy (miles per gallon) before and after installation of the conversion kit was comparable for any given fuel (E0 and E20). As expected, fuel economy with ethanol blends decreased with increasing ethanol content due to the lower energy density of ethanol. These results are consistent with previous ethanol studies. $^{* \dagger}$

Some 8 million FFVs have been sold in the United States, and all models were emissions certified on Federal Certification Gasoline and on E85. City (FTP) and Highway (HFET) fuel economy have been determined for each fuel, and these data are available from EPA. ${ }^{\ddagger}$ These data are the basis of the window

*Keith Knoll et al., Effects of Intermediate Ethanol Blends on Legacy Vehicles and Small Non-Road Engines, Report 1Updated, NREL/TP-540-43543/ORNL/TM-2008/117, February 2009, available at http://www.nrel.gov/docs/fy09osti/43543.pdf

${ }^{\dagger}$ Brian H. West et al., Intermediate Ethanol Blends Catalyst Durability Program, ORNL/TM-2011/234, February 2012, available at http://www.osti.gov/bridge/servlets/purl/1035578/1035578.pdf.

${ }^{\ddagger}$ U.S. Environmental Protection Agency, Test Car List Data Files, available at http://www.epa.gov/otaq/tcldata.htm. 
sticker fuel economies for new vehicles and the annual Fuel Economy Guide. ${ }^{*}$ Data shown in the Fuel Economy Guide are adjusted to reflect fuel economy closer to what consumers might expect and also rounded to an integer value; raw fuel economy values from the actual tests are often referred to as unadjusted results. Unadjusted data from model years 2000-2011 were collected from the EPA website to develop a fuel economy database for U.S.-legal FFVs.

The fuel economy data records for all vehicles evaluated on ethanol (E85) were located and matched with corresponding fuel economy data for the same vehicles tested with federal certification gasoline. For model years 2000-2011, more than 600 city and highway fuel economy records for U.S. light duty FFVs were taken from the EPA database and are plotted in Figure 4. Reported E85 fuel economy is plotted versus certification (E0) gasoline fuel economy. The slopes of the regressions indicate the expected 25\%$30 \%$ loss in tank mileage due to the lower energy density of E85 compared to E0.

The converted flex-fuel Charger data are also shown in Fig. 4 and exhibit the same 27\% tank mileage loss with E85 when compared to E0. Note that in the field most gasoline is E10, which would narrow the fuel economy gap slightly. Also, because fuel for flex fuel vehicles can range from 51 to $83 \mathrm{vol} \%$ ethanol, actual mileage reductions will vary widely, being correspondingly higher with increasing ethanol concentration.

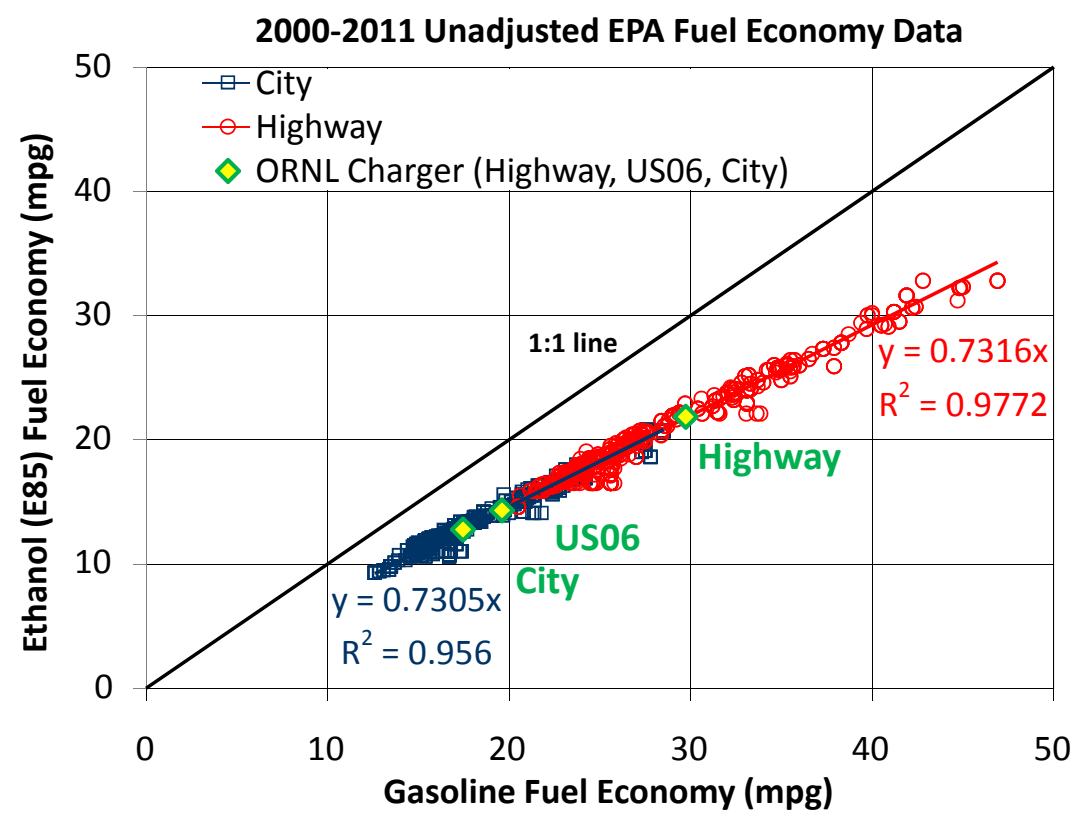

Fig. 4. E85 fuel economy versus gasoline fuel economy for U.S.Legal FFVs.

*U.S. Department of Energy, Fuel Economy Guide, available at http://www.fueleconomy.gov/feg/printGuides.shtml. 


\subsection{EXHAUST EMISSIONS}

Emissions of $\mathrm{NO}_{\mathrm{X}}, \mathrm{CO}, \mathrm{THC}^{*}$ and methane were measured for each drive cycle test. Figures 5 and 6 show the $\mathrm{NO}_{\mathrm{X}}$ and $\mathrm{CO}$ emissions. Columns in Figs. 5 and 6 show average emissions, and the range bars show the maximum and minimum of multiple tests.
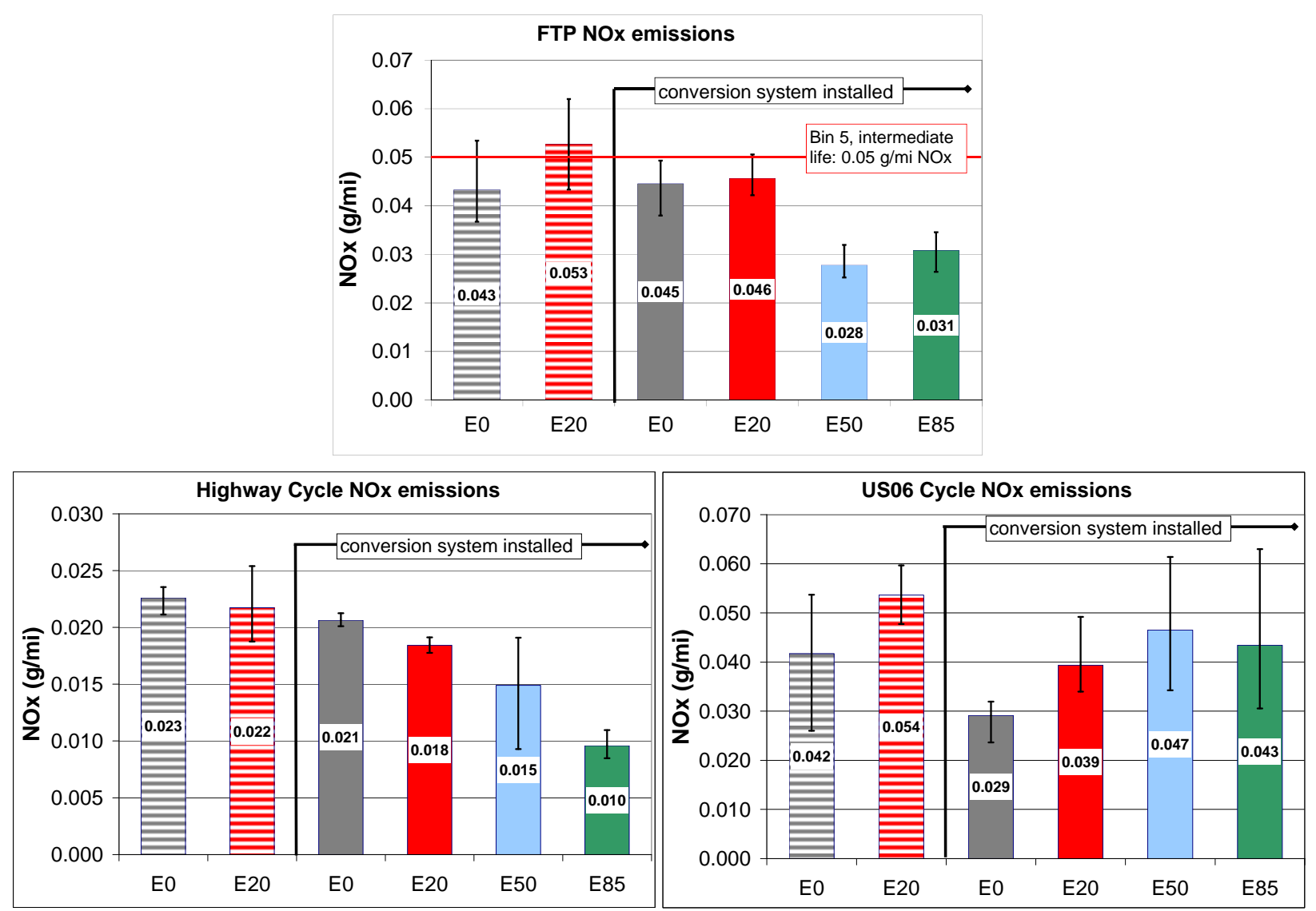

Fig. 5. Average $\mathrm{NO}_{\mathrm{X}}$ emissions for test fuels over the FTP, HFET, and US06 drive cycles before and after conversion kit installation. Range bars show maximum and minimum test results.

Ethanol, formaldehyde, acetaldehyde, THC, and methane were used to estimate NMOG, as shown in Fig. 7. Only the FTP results are shown in Fig. 7; NMOG results for the hot start HFET and US06 cycles were on the order of 1 to $5 \mathrm{mg} / \mathrm{mile}$, and most of the oxygenated species were virtually undetectable. The NMOG exhaust emissions on E0 and E20 were similar before and after installation of the conversion kit.

\footnotetext{
*THC (total hydrocarbons) is commonly used to indicate the flame ionization detector (FID) HC and is technically a misnomer because all HC cannot be accounted for by FID. NMOG emissions are estimated by first subtracting methane and known oxygenated species from the THC (FIDHC) measurement after accounting for known response factors of the various species; this result is the nonoxygenated nonmethane HC (NONMHC). NMOG is then calculated by adding the known oxygenated species mass measurements back to the NONMHC mass. This protocol is described in Effects of Intermediate Ethanol Blends on Legacy Vehicles and Small Non-Road Engines, Report 1—Updated, NREL/TP-540-43543/ORNL/TM-2008/117, February 2009, available at http://www.nrel.gov/docs/fy09osti/43543.pdf.
} 

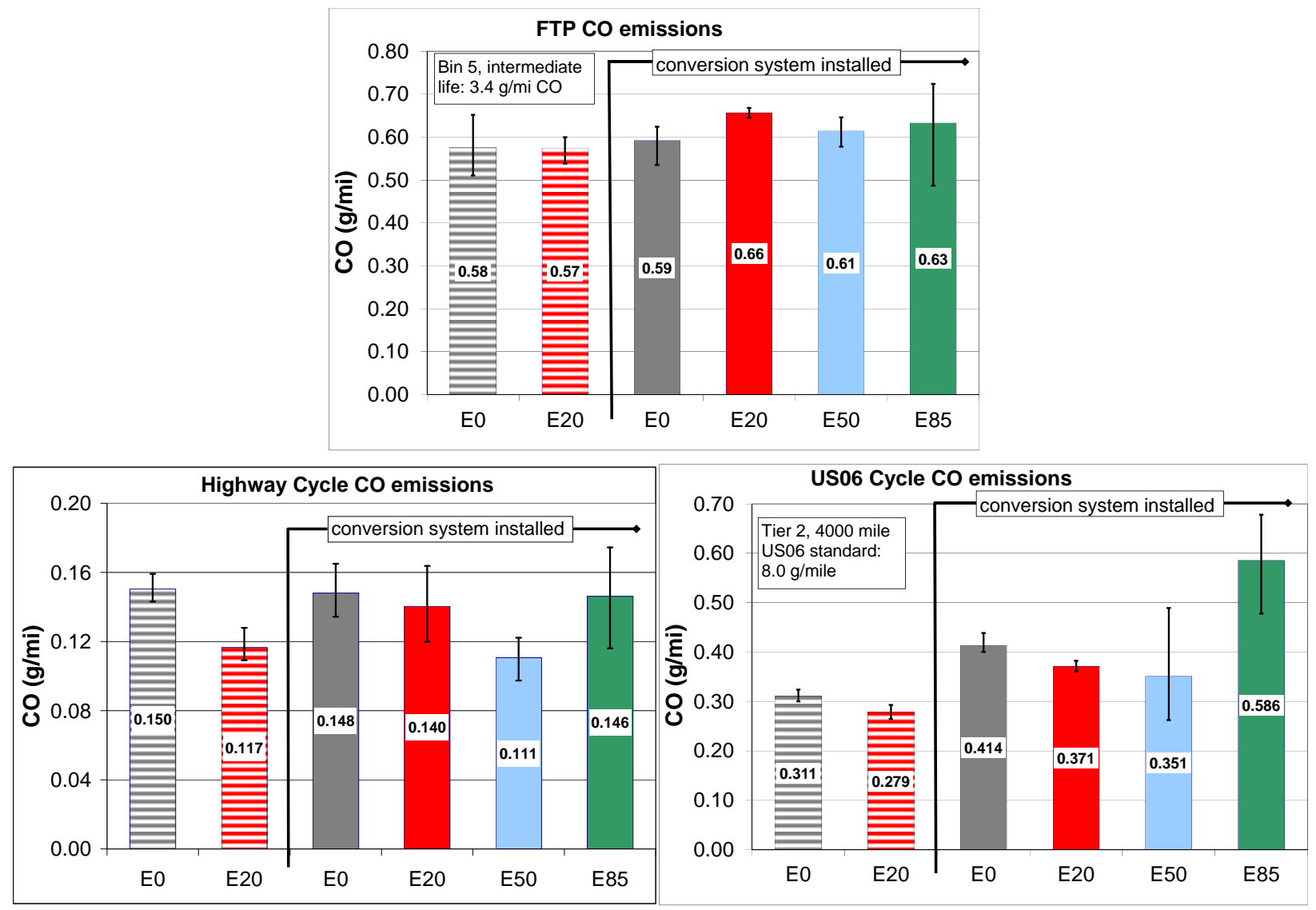

Fig. 6. Average CO emissions for test fuels over the FTP, HFET, and US06 drive cycles before and after conversion kit installation. Range bars show maximum and minimum test results.

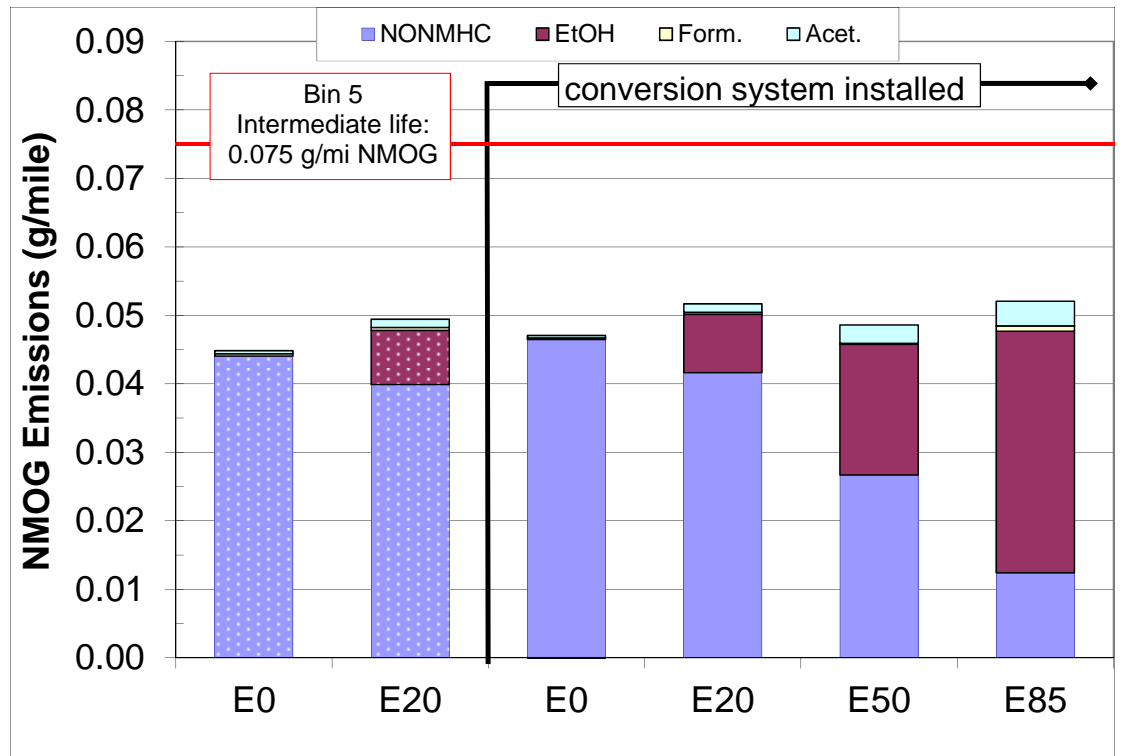

Fig. 7. Average FTP NMOG emissions with breakdown for nonoxygenated nonmethane hydrocarbons (NONMHC), ethanol (EtOH), formaldehyde (Form.) and acetaldehyde (Acet.). 
Average results for all measured emissions on all tests, with one exception, were within the regulated EPA limits for this vehicle (Tier 2/Bin 5). The average of the E20 fuel FTP $\mathrm{NO}_{\mathrm{X}}$ baseline results (before FFV conversion) was slightly above the Bin 5 intermediate life standard of $0.05 \mathrm{~g} / \mathrm{mile}$, as shown in Fig. 5. Note that E20 is not a legal fuel for the unaltered vehicle and that statistically significant increases in $\mathrm{NO}_{\mathrm{X}}$ with ethanol blends have been noted in previous studies with non-FFVs. ${ }^{\dagger \ddagger}$ It is also worth noting that all E0 and E20 $\mathrm{NO}_{\mathrm{X}}$ emissions ranged from $73 \%$ to $124 \%$ of the $0.05 \mathrm{~g} / \mathrm{mile}$ standard, and certain individual tests exceeded the standard both before and after conversion (one E0 test before conversion, two E20 tests before conversion, and one E20 test after conversion). Test-to-test variability of this magnitude is not uncommon for Tier 2 vehicles. ${ }^{\ddagger}$

Nitrogen oxide emissions decreased with increased ethanol fueling on the HFET and FTP tests, presumably due to lower combustion temperatures. Nitrogen oxide emissions on the US06 test varied widely but were relatively low considering the 4,000 mile $\mathrm{NMHC}+\mathrm{NO}_{\mathrm{X}}$ limit of $0.14 \mathrm{~g} / \mathrm{mile}$ and the extremely low NMHC emissions. Carbon monoxide emissions were quite low in all cases, being on the order of $15 \%$ to $25 \%$ of the intermediate life Tier 2/Bin 5 FTP standard of $3.4 \mathrm{~g} / \mathrm{mile}$ and less than onetenth of the US06 standard of $8.0 \mathrm{~g} /$ mile. Emissions of $\mathrm{NO}_{\mathrm{x}}$ and NMOG were much closer to the EPA intermediate life limits for this vehicle on the FTP drive cycle, as shown in Figs. 5 and 7.

\subsection{WIDE-OPEN-THROTTLE STUDY}

The modified CRC E-60 WOT protocol was conducted at each of the conditions in Table 2. A speed trace for the WOT test is shown in Fig. 8. The purpose of the WOT test is to characterize enrichment during open-loop operation. In recent studies by the Coordinating Research Council (CRC) and the U.S. Department of Energy (DOE), ${ }^{\beta^{* *}}$ vehicles that do not apply long-term fuel trim at WOT were found to have hotter exhaust and catalyst temperatures when fueled with ethanol blends; there is concern that higher catalyst temperatures can increase the deterioration rate of vehicle emissions over time from thermal damage to the catalyst and/or oxygen sensors. ${ }^{+\dagger}$

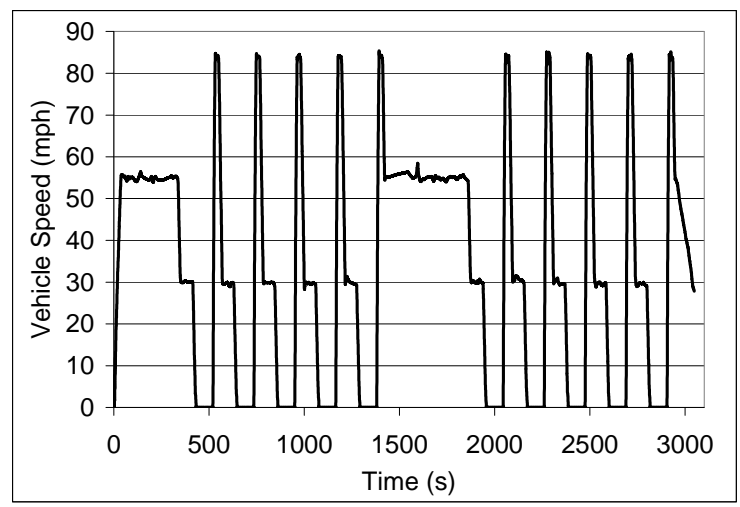

Fig. 8. WOT test protocol.

\footnotetext{
*EPA emissions regulations, available at http://www.epa.gov/otaq/standards/light-duty/tier2stds.htm.

${ }^{\dagger}$ Knoll, Keith, Brian West, Shean Huff, John Thomas, John Orban, Cynthia Cooper, "Effects of Mid-Level Ethanol Blends on Conventional Vehicle Emissions,” Society of Automotive Engineers Paper 2009-01-2723, November 2009.

${ }^{\ddagger}$ Brian H. West et al., Intermediate Ethanol Blends Catalyst Durability Program, ORNL/TM-2011/234, Oak Ridge National Laboratory, Oak Ridge, Tennessee, February 2012.

${ }^{\S}$ CRC Report: E-87-1, Mid-Level Ethanol Blends Catalyst Durability Study Screening, June 2009.

*** ORNL/TM-2008/117, February 2009, available at http://www.nrel.gov/docs/fy09osti/43543.pdf

${ }^{\dagger \dagger}$ Technical Issues Associated with the Use of Intermediate Ethanol Blends (>E10) in the U.S. Legacy Fleet, ORNL/TM-2007/37, August 2007.
} 


\section{Fuel Effects on Catalyst Temperature}

Figure 9 shows catalyst temperature for E0 and E20 fuels for the OEM condition (before conversion kit installation). Consistent with other Chrysler vehicles tested in previous studies, it appears that the Charger does not apply learned fuel trim at WOT, as indicated by the higher catalyst temperature for the E20 fuel (which shows an average peak temperature increase of about $15^{\circ} \mathrm{C}$ ). After the kit conversion, this temperature increase was less apparent, as seen in Figure 10. With E50 and E81 fuels there are still incidents of increased exhaust temperature compared to E0, but not consistently so, and peak temperatures are no hotter than the OEM condition with E20. These results indicate that the aftermarket kit is adding fuel to compensate for the lower energy density of ethanol during open-loop operation.
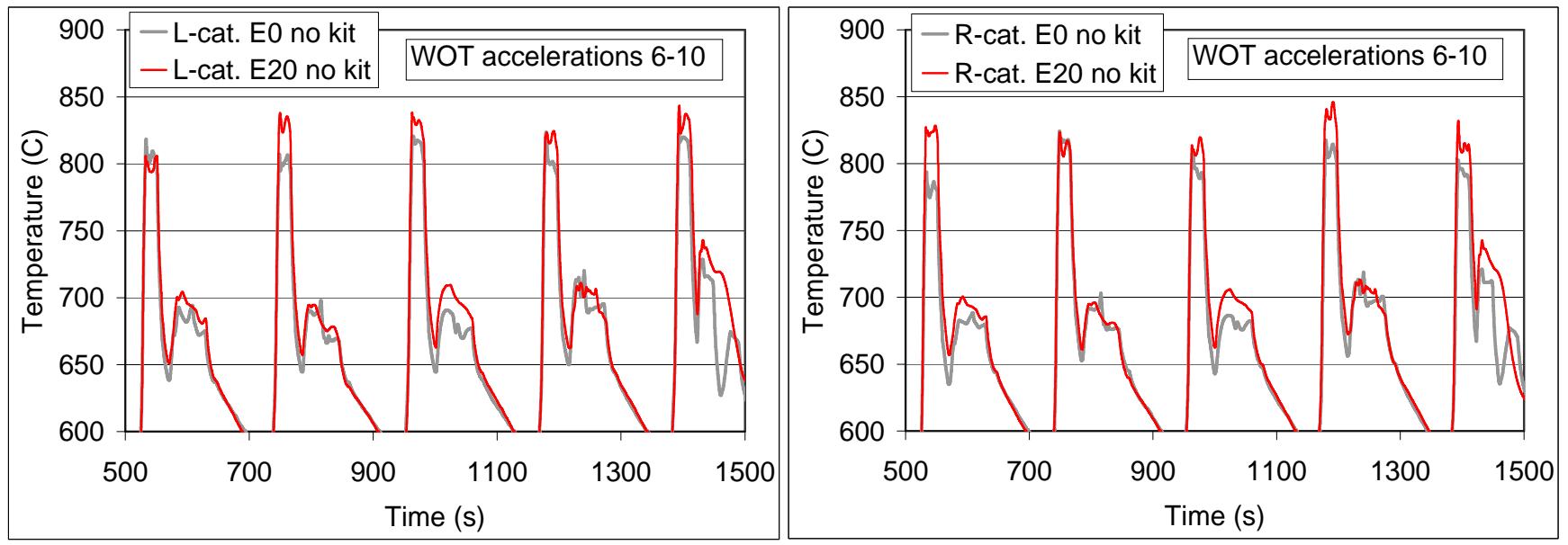

Fig. 9. Catalyst temperature for E0 and E20 fuels during WOT testing in the OEM condition.
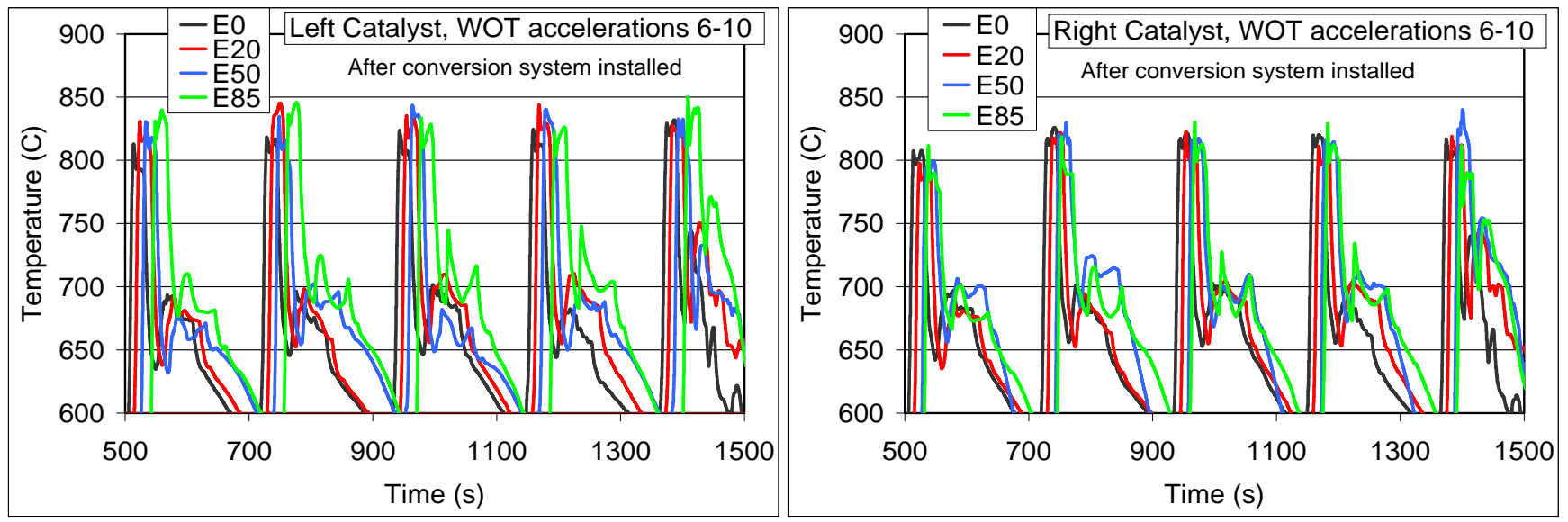

Fig. 10. Catalyst temperature for each fuel during WOT testing after installation of FFV kit. The peak temperatures appear similar for each fuel.

\section{Acceleration performance}

The WOT testing also allowed examination of any changes in acceleration performance. Times were determined for accelerations from 20 to $80 \mathrm{mph}$. This interval was chosen to ensure that the vehicle was fully at WOT and to remove driver induced variability that might occur for a standing start type test. The acceleration times, shown in Fig. 11, indicate a small but measureable performance improvement with 
increased fuel ethanol content. An improvement of about 0.5 seconds or $6 \%$ is seen for the E85 fuel versus the certification fuel (E0). Ethanol's higher latent heat of vaporization improves volumetric efficiency, thus increasing power at the WOT condition. While an optimized FFV may advance ignition timing to take advantage of ethanol's higher octane, thus improving power and efficiency, ${ }^{*}$ the Dodge Charger conversion does not appear to adjust ignition timing. Spark timing records for WOT experiments indicate similar spark advance for all fuels.

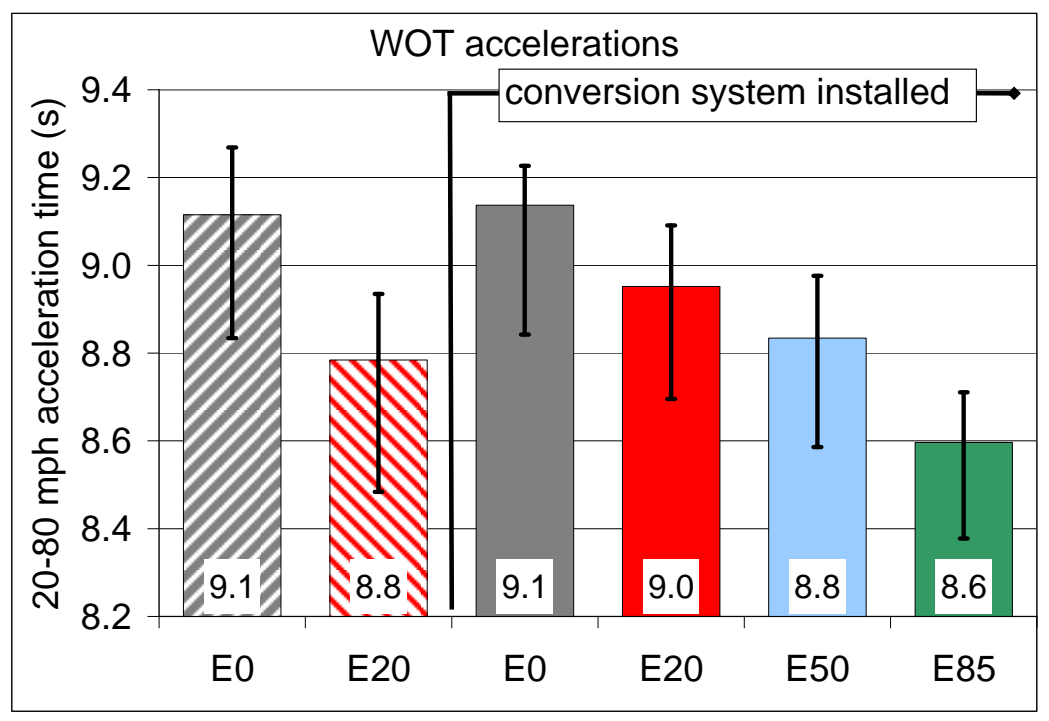

Fig. 11. WOT acceleration times from $20 \mathrm{mph}$ to $80 \mathrm{mph}$ for all fuels. Range bars show maximum and minimum test results.

\subsection{TESTING ISSUES}

The Dodge Charger OEM fuel tank is of the saddlebag design and has essentially two sumps and two fuel pumps. Flushing the factory tank is a time consuming process and wastes large volumes of fuel. To expedite the fuel change process, tests on the Charger were conducted with off-board fueling, as described above. Unfortunately, poor filtration with the off-board system led to fuel injector clogging that became apparent during the E85 tests [malfunction indicator light (MIL, or “check engine” light) illumination indicated a problem]. The fuel injectors were changed, improved filtration was installed, and emissions tests were repeated. Following emissions tests, the E85 WOT protocol was run. The MIL illuminated again during the WOT tests (same MIL code). The problem was again determined to be clogged fuel injectors. The test was repeated after changing fuel injectors.

\section{SUMMARY/CONCLUSIONS}

An aftermarket kit designed to convert a conventional gasoline 2006 Dodge Charger to flexible-fuel operation was evaluated in FTP, HFET, and US06 drive cycle tests at a nominal temperature of $77^{\circ} \mathrm{F}$ to assess fuel economy and short-term tailpipe emissions performance of the vehicle before and after FFV conversion. Baseline tests with E0 and E20 were conducted in the OEM condition, and tests after FFV conversion were conducted with E0, E20, E50, and E81 test fuels. The following results were obtained.

*B. H. West, et al., "Fuel Economy and Emissions of the Ethanol-Optimized Saab 9-5 BioPower," Society of Automotive Engineers Paper 2007-01-3994, October 2007. 
- Fuel economy decreased with increasing fuel ethanol content, as expected. The fuel economy decrease was commensurate with the energy density of the test fuels.

- Carbon monoxide and NMOG emissions were largely unchanged with ethanol fueling, both before and after installation of the flex-fuel kit.

- Average NOx emissions exceeded the Tier 2/Bin 5 intermediate life $\mathrm{NO}_{\mathrm{x}}$ standard with $\mathrm{E} 20$ fuel in the OEM condition due to two of three test results exceeding this standard [note that E20 is not a legal fuel for non-flexible-fuel vehicles (non-FFVs)]. In addition, one E0 test result before conversion and one E20 test result after conversion exceeded the $\mathrm{NO}_{\mathrm{X}}$ standard (although the average result in these two cases was below the standard).

- Nitrogen oxide emissions appeared to decrease with E50 and E81 on the HFET and FTP tests (after installation of the flex-fuel kit), presumably due to the lower combustion temperatures associated with ethanol.

- Emissions of ethanol and acetaldehyde increased with increased ethanol fueling in all cases.

- Increased ethanol fueling resulted in a slight improvement in WOT acceleration, presumably due to charge cooling.

Emissions conformity is only one area that must be addressed when dealing with aftermarket modifications to a vehicle, but it was the focus of this study. Other subject areas such as cold weather starting, durability, and materials compatibility with ethanol blends were not assessed. These results reflect the performance of a specific aftermarket flexible-fuel conversion kit installed on one 2006 model year Dodge Charger test vehicle equipped with a specific engine and drive train configuration. No conclusions can be drawn or inferred regarding the installation or performance of this or any other conversion kit installed on other vehicles equipped with similar or different engines and/or drivetrain configurations.

\section{ACKNOWLEDGMENTS}

This report and the work described were sponsored by the DOE Office of Energy Efficiency and Renewable Energy Vehicle Technologies Program. The authors gratefully acknowledge the support and direction of Dennis Smith at DOE. We acknowledge and appreciate the thorough review and input from Steve Przesmitzki at DOE, Scott Sluder and John Storey at ORNL, Beth Ardisana and Max Moore at ASG Renaissance, Marc Goodman at New West Technologies, Martin Reineman at EPA, and others. We are also grateful to Janet Hopson for her help with the EPA database and to Larry Moore for his assistance with vehicle setup and laboratory operation. We are similarly indebted to V. J. Ewing and Kathy Jones for their dedicated and enthusiastic support in preparation of the final manuscript.

The authors are indebted to several technical experts in industry and government for their input, guidance, and peer review. While these experts provided valuable guidance and information as noted above, this consultation does not constitute endorsement by their organizations of either the study or the results. 